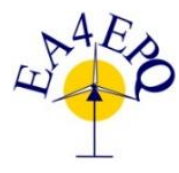

$1^{\text {th }}$ International Conference on Renewable Energies and Power Quality (ICREPQ'20)

Granada (Spain), $1^{\text {st }}$ to $2^{\text {nd }}$ April 2020

Renewable Energy and Power Quality Journal (RE\&PQJ)

\title{
Capacity Credit of Solar PV Projects - Oman's Main Interconnected System Case Study
}

\author{
M. Albadi, A. Malik, T. Al Rashdi, A. Al Riyami, O. Al Shukaili \\ Department of Electrical and Computer Engineering, Sultan Qaboos University, PO Box 33, Muscat 132, Oman \\ e-mail: mbadi@squ.edu.om
}

\begin{abstract}
Due to high growth in electricity demand, it is important to add more dispatchable generation capacity in power systems to maintain demand-supply balance in real time. In many power systems, fossil fuel-based units such as gas or coal power plants are used to maintain high-reliability standards during peak demand hours. Although intermittent renewable energy generation facilities such as solar PV systems are used as a fuel saver, they can offset part of the load during peak hours. Capacity credit measures the contribution of a power plant to reliably meet demand. Estimating capacity credit of solar PV systems is important to ensure the adequacy and security of electricity supply. In this article, the capacity credit of solar PV power plants in the Main Interconnected System (MIS) of Oman is modelled. Oman's MIS considered in this study has 6,372 MW gas-based generation capacity, a negligible solar PV capacity, and 5,712 MW peak load. The results revealed that the capacity credit of solar PV plants is high at low solar PV penetration levels. However, it decreases drastically as solar PV capacity increases. For example, the first 500MW plant has a capacity credit of about $120 \mathrm{MW}$. When the cumulative installed solar PV capacity is $2000 \mathrm{MW}$, the next $500 \mathrm{MW}$ plant has a capacity credit of only $26 \mathrm{MW}$.
\end{abstract}

\section{Keywords}

Renewable Energy; Solar PV; Capacity Credit; Main Interconnected System.

\section{Introduction}

Power generation from renewable resources solar power varies from hour to hour according to prevailing weather conditions. This is different to fossil-fuel generators, which can normally be dispatched according to their operators' preferences. In a competitive market, they can choose to generate when spot prices are sufficiently high. As the penetration of variable renewable generation technologies increases, the variable nature of their output will become a more important feature of power systems. In particular, it will have an impact on the amount of capacity required to be installed to meet peak system demand, and on the operating patterns of other generators [1].

Capacity credit or value or sometime called effective capacity is defined as the amount of additional load that can be served due to the addition of the generating unit, while maintaining the existing levels of reliability [2]. Alternatively, the amount of conventional generation the alternate energy source would replace without appreciable change in system performance [3]. Yet another definition is the amount of power (as an average output of the plant) which Transmission System Operator (TSO) expects. The Organization for Economic Cooperation \& Development (OECD) and the International Energy Agency (IEA) define the capacity credit as the amount of variable renewable energy power that can reliably be expected at the times when demand for electricity is highest. The National Renewable Energy Laboratory (NREL) defines the capacity credit as the contribution of a power plant to reliably meet demand. According to the European Wind Energy Association (EWEA), the capacity credit of renewable energy is measured against the outage probabilities of conventional power plants. In special cases, PJM interconnection and New York Independent System Operator (NYISO) define capacity credit as the capacity factor during the daily peak load hours of the peak load months. Capacity credit is measured in term of $\mathrm{kW}, \mathrm{MW}$ or GW. On other hand, capacity factor is the measurement of the average production of generation unit over a period as a percentage from its installed capacity [4]. It is important to determine the capacity value of generation resource to ensure that the system reliability met during power generation planning [5].

Reference [6] provides a review of solar capacity evaluation whereas [7] is an updated survey of methods and implementation of capacity value of wind. Authors of [8] presents practical experience in 
evaluating the adequacy of generating capacity by different regions in the Western interconnection. This includes an analysis of uncertainties associated with load, intermittent energy sources, and forced and maintenance outages on generating units and transmission facilities. Reference [9] provides a framework for capacity credit assessment of electrical energy storage and demand response. The impact of battery storage and solar PV installation on capacity credit improvement is investigated in [10]. This paper presents an approximate method of capacity factor to evaluate the capacity credit of committed solar PV plant of $500 \mathrm{MW}$ in Main Interconnected System (MIS) of Oman.

In the MIS of Oman, power plants are supplied with natural gas by the Ministry of Oil and Gas (MOG). During the period from 2005 to 2014, natural gas production increased by $51 \%$ [11]. However, because of the substantial increase in natural gas consumption in energy-intensive industries, liquefied natural gas (LNG) exports decreased by $12 \%$ [11]. Although the contribution of renewable energy in the electricity supply mix is very small, several published studies have emphasized the potential of solar and wind resources in Oman.

Due to the fact that natural gas resources are tight and committed, policy maker in Oman are seeking to diversify electricity supply mix. In 2017, Council of Financial Affairs and Energy Resources (CFAER) approved a new national energy policy that mandates to have $10 \%$ minimum contribution of renewable energy in electricity supply mix by 2025 . To reach this objective, the Authority for Electricity Regulation (AER) in Oman announced Sahim roof-top solar PV program in 2017. In 2018, the National Program for Enhancing Economic Diversification mandated that $11 \%$ of the country's electricity requirements through renewable energy sources by 2023. Oman Power and Water Procurement Company (OPWP) floated a tender in 2018 for a 500MW solar PV plant in Ibri. This solar plant is to be operational by 2021 [12-13]. Similar solar IPP projects are planned to be commissioned in 2022, 2023, and 2024.

Estimating capacity credit (value) of solar PV power is very important to ensure supply adequacy and security. The objective of this paper is to estimate capacity credit of committed and candidate Solar PV projects in Oman's Main Interconnected System.

\section{Capacity Credit Evaluation Methods}

There are several methods that can be used for estimating the capacity credit of a renewable energy project. In general, both generation and load models are required. The evaluation of capacity credit starts with forming the generation and load curves for knowing the capacity of generation system against the changes of load profile. The overall reliability of the system is then computed. After getting the system reliability at different operating points, the output of intermittent resource is used to calculate net load and the reliability of the power system is assessed again. The capacity credit of intermittent resource is obtained by comparing the system reliability with and without the intermittent renewable energy resource.

Methods for evaluating the capacity credit of renewable resources are often classified into two major categories as shown in Fig. 1. These categories differ in terms of process complexity and data requirements. The first category is reliability-based methods and includes Equivalent Conventional Power (ECP), Effective Load Carrying Capability (ELCC), and Equivalent Firm Capacity (EFC). These methods use power system reliability evaluation techniques, that include Loss of Load Probability (LOLP) and Loss of Load Expectation (LOLE) calculations. LOLP is the likelihood of a loss of load event during which the system load is larger than the available generating capacity throughout a given period. LOLP is usually computed in one-hour increments. The LOLE is the sum of the LOLPs throughout a planning period, typically one year. LOLE offers the expected range of time periods within which a loss of load event happens. Power system planners usually aims to maintain a pre-specified LOLE value, for example 0.1 days/year [14].

The second category uses approximations and are less complicated but varies in accuracy. These methods include Garver's ELCC approximation, Z-method, and capacity factor-based methods. These methods involve modeling conventional generator outages using an Equivalent Forced Outage Rate (EFOR). EFOR is the probability that a selected generator will experience a failure at any given time. Once renewables are added to a system, the system reliability models should also capture the variability of real-time resource availability. To do this, renewable resource availability is usually anticipated using historical information or by simulating such information [14].

Capacity factor approximation method considers the capacity factor of a generator over of a part of period while the system is facing a high risk of an outage events. This method was applied due to its simplicity and accuracy. There are three different approximation methods that differ based on the set of hours examined. The first one uses the average capacity factor during the peak-load hours. The second one uses the capacity 
factor during the peak-LOLP hours. The third one uses the highest-load hours and normalizes the capacity factors using LOLPs in order to give more weight for the contribution during hours with high LOLPs [14]. Due to its accuracy, the third method is used in this study. The authors of [14] suggest the $10-30 \%$ of hours yield sufficient accuracy. In this study, all hours are used and capacity factors are normalized using LOLPs to improve accuracy.

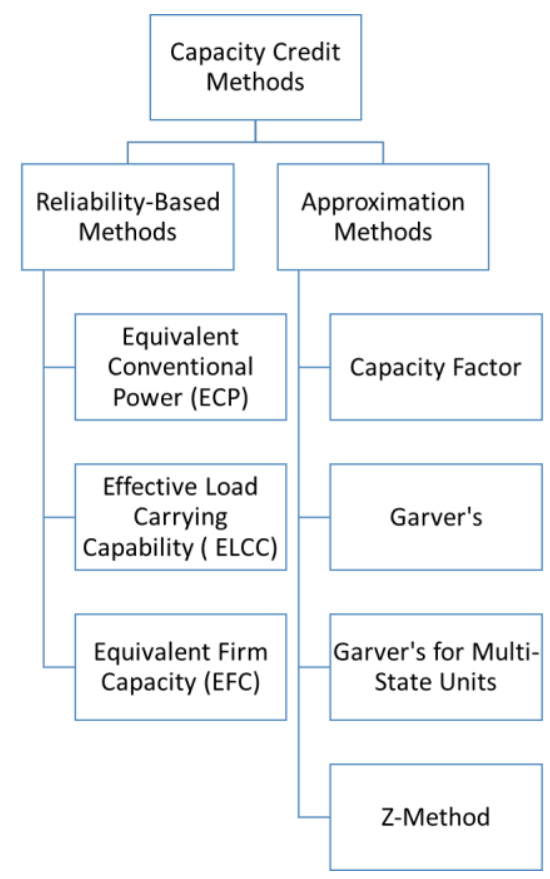

Fig. 1. Classification of capacity credit calculation methods

\section{Capacity Factor Approximation Method - Simple Example}

To highlight the calculation steps, a simple 3-unit test system is considered as shown in table 1 .

\section{- Step\#1: Outage State Estimation}

This method starts with calculating units' availabilities from Forced Outage Rates data (FOR) of the generation system.

Availability $=1-$ FOR

Table 1 Generating System of 3 Units

\begin{tabular}{|c|c|c|c|}
\hline Units & $\begin{array}{c}\text { Max. Net Available } \\
\text { Power } \\
\text { MW }\end{array}$ & FOR & Availability \\
\hline A & 100 & 0.03 & 0.97 \\
\hline B & 200 & 0.05 & 0.95 \\
\hline C & 300 & 0.07 & 0.93 \\
\hline Total & 600 & \multicolumn{2}{|l}{} \\
\hline
\end{tabular}

The probability of the units to be in service or on outage at different loading conditions are calculated as shown in Table 2.

Table 2 Outage State Estimation

\begin{tabular}{|l|l|l|l|l|}
\hline $\begin{array}{l}\text { On } \\
\text { Outage }\end{array}$ & $\begin{array}{l}\text { X MW on } \\
\text { Outage }\end{array}$ & In service & Probability & $\begin{array}{l}\text { Probability of } \\
\text { X MW or } \\
\text { More on } \\
\text { Outage }\end{array}$ \\
\hline None & 0 & A,B,C & 0.857000 & 1.000000 \\
\hline A & 100 & B,C & 0.026505 & 0.143005 \\
\hline B & 200 & A,C & 0.045105 & 0.116500 \\
\hline C & 300 & A,B & 0.064505 & 0.071395 \\
\hline A,B & 300 & C & 0.001395 & 0.006890 \\
\hline A,C & 400 & B & 0.001995 & 0.005495 \\
\hline B,C & 500 & A & 0.003395 & 0.003500 \\
\hline A,B,C & 600 & None & 0.000105 & 0.000105 \\
\hline Total & & 1.00000 & \\
\hline
\end{tabular}

The probability of a given outage configuration is obtained by multiplying the availability of the units in service and FOR of the units on outage. The Probability of X MW or more on outage is calculated as following. First row is the sum of all probabilities second row is the previous cell minus the first probability and so on.

\section{- $\quad$ Step \# 2: LOLP calculation without PV power}

Table 3 shows the daily peak of one-week load profile. The capacity or more on outage (column 3 of table 3 ) is obtained by subtracting each daily peak load from the available system generation capacity of $600 \mathrm{MW}$. The LOLP in column 4 of table 3 is obtained by inspecting columns 2 and 5 of Table 2. For example, LOLP of 0.0035 (column 4 in Table 3 ) of $480 \mathrm{MW}$ or more on outage corresponds to the probability of $\mathrm{X}$ MW or more on outage of $500 \mathrm{MW}$ from Table 2.

Table 3 Index of LOLP

\begin{tabular}{|l|l|l|l|}
\hline \multirow{5}{*}{ Day } & $\begin{array}{l}\text { Daily } \\
\text { Peak } \\
\text { Load } \\
(M W)\end{array}$ & $\begin{array}{l}\text { Capacity or More } \\
\text { on Outage }(M W) \\
(600-\text { Daily Peak } \\
\text { Load })\end{array}$ & $\begin{array}{l}\text { Probability of not } \\
\text { Meeting } \\
(\text { LOLP) }\end{array}$ \\
\hline Sunday & 120 & 480 & 0.003500 \\
\hline Monday & 170 & 430 & 0.003500 \\
\hline Tuesday & 250 & 350 & 0.005495 \\
\hline Wednesday & 330 & 270 & 0.006890 \\
\hline Thursday & 390 & 210 & 0.006890 \\
\hline Friday & 440 & 160 & 0.116500 \\
\hline Saturday & 490 & 110 & 0.116500 \\
\hline \multicolumn{3}{|r|}{ Total } & $\mathbf{0 . 2 5 9 2 7 5}$ \\
\hline
\end{tabular}

- $\quad$ Step \# 3: LOLP with PV system

Table 4 assumes that the solar PV system produces power between 88.598 and 96.876 MW during daily peak time (column 2). This production is considered as a negative load as it will reduce the net load seen by the generation system. Therefore, it is expected that 
capacity credit of this PV system is between 88.598 and 96.876 MW.

The new net daily peak load become less by the PV system output compared with the load before adding the solar PV system. The probability of not meeting the load or LOLP is calculated again for the system as follows. The capacity or more on outage will be the whole system power (600 MW) minus the net load after adding solar PV power. The LOLP with the PV system is obtained from columns 2 and 5 in Table 2 . For example, if the capacity or more on outage equal to $570.123 \mathrm{MW}$ (column 4 of table 4), take the probability of X MW or more on outage of $600 \mathrm{MW}$ from Table 2 and fill it on column 5 of Table 4 . From Tables 3 and 4, it is clear that the $L O L P$ after adding PV system is less than the previous LOLP.

Table 4 Index of LOLP with PV

\begin{tabular}{|c|c|c|c|c|}
\hline Day & $\begin{array}{l}\text { PV } \\
\text { Output } \\
(M W)\end{array}$ & $\begin{array}{ll}\text { Net } & \text { Daily } \\
\text { Peak } & \text { Load } \\
\text { (MW) } & \text { (with } \\
\text { PVoutput) }\end{array}$ & $\begin{array}{l}\text { Capacity or } \\
\text { More } \\
\text { Outage }(M W)\end{array}$ & $\begin{array}{l}\text { Probability of } \\
\text { not Meeting } \\
\text { Load (LOLP } \\
\text { with PV) }\end{array}$ \\
\hline Sunday & 90.123 & 29.877 & 570.123 & 0.000105 \\
\hline Monday & 93.786 & 76.214 & 523.786 & 0.000105 \\
\hline Tuesday & 91.772 & 158.228 & 441.772 & 0.0035 \\
\hline Wednesday & 88.598 & 241.402 & 358.598 & 0.005495 \\
\hline Thursday & 94.546 & 295.454 & 304.546 & 0.005495 \\
\hline Friday & 96.876 & 343.124 & 256.876 & 0.071395 \\
\hline Saturday & 95.112 & 394.888 & 205.112 & 0.071395 \\
\hline \multicolumn{4}{|r|}{ Total } & 0.15749 \\
\hline
\end{tabular}

- $\quad$ Step \# 4: Calculate the Capacity Credit

Table 5 shows the capacity credit $C C$ which is calculated using the following equations:

$w_{i}=\frac{L O L P_{i}}{\sum_{j=1}^{T} L O L P_{j}}$

Where $w_{i}$ is the weight in hours $i, L O L P_{i}$ is the $L O L P$ in hours $i$ and $T$ is the number of hours in the research. The average weighted generation, $\beta_{i}$, of the PV plant in the highest load-hours is calculated from pervious weights and PV output $\left(P V_{i}\right)$ during those hours as follows:

Table 5 Capacity Credit Calculation example

\begin{tabular}{|c|c|c|c|}
\hline Day & $\begin{array}{c}\text { Sum } \\
\text { LOLP }\end{array}$ & $w_{i}$ & $\beta_{i}$ \\
\hline Sunday & \multirow{7}{*}{0.15749} & 0.000667 & 0.060085815 \\
\hline Monday & & 0.000667 & 0.06252797 \\
\hline Tuesday & & 0.022224 & 2.03950727 \\
\hline Wednesday & & 0.034891 & 3.09128205 \\
\hline Thursday & & 0.034891 & 3.298814337 \\
\hline Friday & & 0.45333 & 43.91683294 \\
\hline Saturday & & 0.45333 & 43.11715817 \\
\hline & & $C C$ & 95.59 \\
\hline
\end{tabular}

$\beta_{i}=w_{i} P V_{i}$

$C C=\sum_{i=1}^{T \prime} \beta_{i}$

Where $T^{\prime}$ is the number of hours used in approximation and $\beta_{i}$ is the weighted generation of the PV plant during the high-load hours [13].

\section{Capacity Credit of PV Solar Projects in MIS}

MATLAB simulation package was used to build a capacity credit model of different solar PV capacities in MIS including the first 500 MW Solar IPP Plant in Ibri. Below is the system data used in this study.

\subsection{MIS Generation Units}

Table 6 represents MIS power plants data. MIS system was represented by an equivalent 21-unit system.

Table 6 Generation Units in MIS

\begin{tabular}{|l|l|l|l|}
\hline Unit Name & Unit Type & Max Net Available Power & FOR \\
\hline & & MW & $\%$ \\
\hline AlKamilGT & GT & 271.299 & 2.0 \\
\hline Barka1_GT & CC (GT) & 249.000 & 2.0 \\
\hline Barka1_ST & CC (ST) & 180.970 & 5.0 \\
\hline Barka2_GT & CC (GT) & 396.000 & 2.0 \\
\hline Barka2_ST & CC (ST) & 279.587 & 5.0 \\
\hline Barka3_GT & CC (GT) & 475.828 & 2.0 \\
\hline Barka3_ST & CC (ST) & 268.880 & 5.0 \\
\hline ManahGT1 & GT & 82.791 & 2.0 \\
\hline ManahGT2 & GT & 179.742 & 2.0 \\
\hline RusailGT1 & GT & 234.108 & 5.0 \\
\hline RusailGT4 & GT & 241.119 & 5.0 \\
\hline RusailGT7 & GT & 92.174 & 5.0 \\
\hline RusailGT8 & GT & 90.948 & 5.0 \\
\hline Sohar1_GT1 & CC (GT) & 415.698 & 2.0 \\
\hline Sohar1_ST & CC (ST) & 169.302 & 5.0 \\
\hline Sohar2_1st GT & CC (GT) & 475.828 & 2.0 \\
\hline Sohar2_ST & CC (ST) & 268.880 & 5.0 \\
\hline Sur GT1 & CC (GT) & $1,222.000$ & 2.0 \\
\hline SurA_ST & CC (ST) & 308.013 & 5.0 \\
\hline SurB_ST & CC (ST) & 311.997 & 5.0 \\
\hline SurC_ST & CC (ST) & 157.990 & 5.0 \\
\hline Total & & $6,372.154$ & \\
\hline & & & \\
\hline & & \\
\hline
\end{tabular}

\subsection{MIS LOAD PV DATA}

The hourly MIS load data for 2015 is shown in Fig. 2. To have more accurate results, all hours were used. The estimated output of a $500 \mathrm{MW}_{\mathrm{p}}$ solar PV plant is described in Fig. 4. The PV output data are based on solar irradiation data provided by the OPWP for the year 2015 [2]. The data of the lowest load and peak load weeks are presented in Fig. 4. 


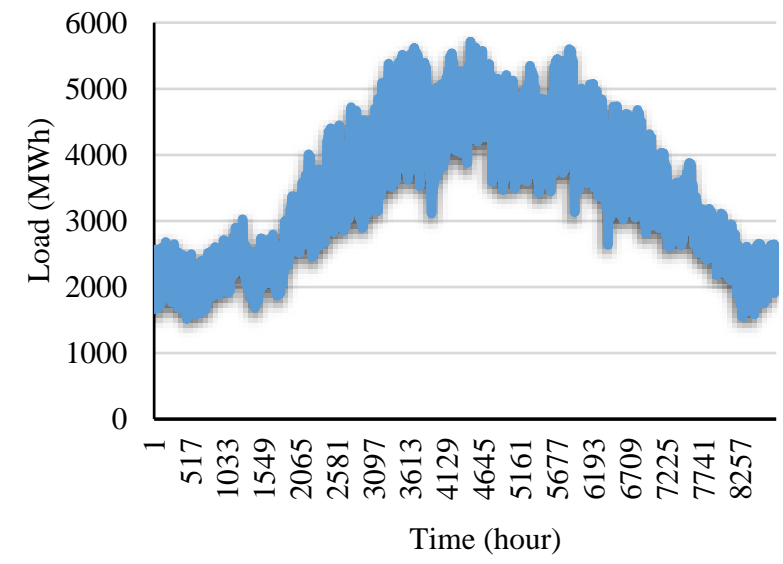

Fig. 2. Hourly MIS load data for 2015

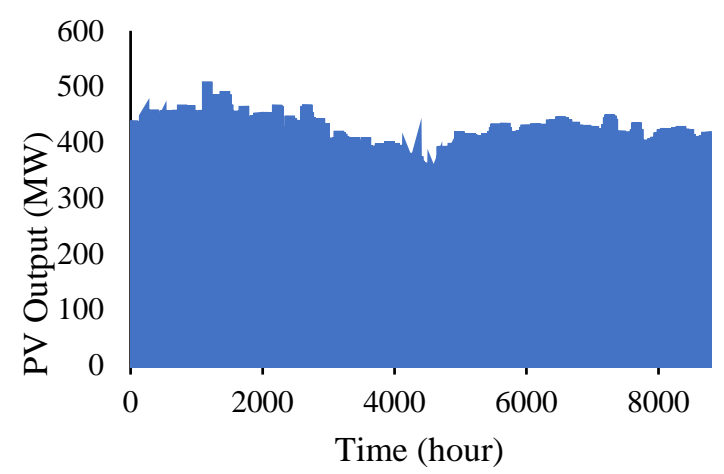

Fig. 3. Hourly PV output based on for 2015 data

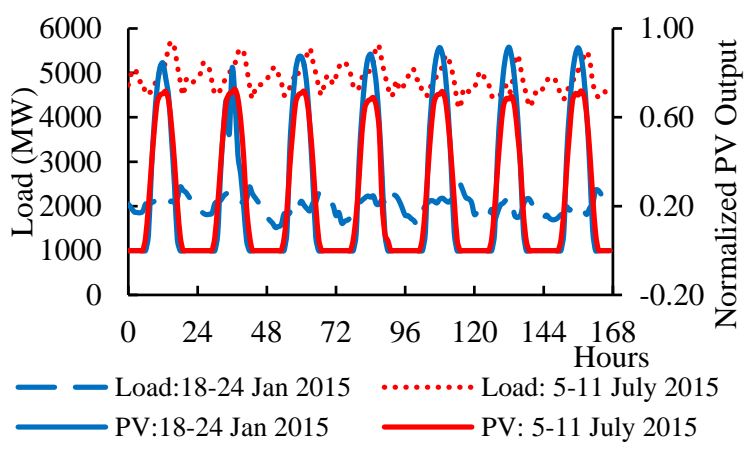

Fig. 4 Hourly load and PV output data for the weeks of the minimum and maximum load.

\subsection{Results}

The capacity of solar PV system increases by $500 \mathrm{MW}$ for each new project as shown in the Table 7. Fig. 5, shows the capacity credit versus the solar capacity in the system. At the beginning, the capacity credit increases proportionally with the solar capacity. However, with higher capacities, the difference between peak load and peak PV output become smaller. This fact results in smaller incremental capacity credit values as the cumulative installed capacity increases. The capacity credit of the first project is $20 \%$ of nameplate capacity while it is only $5 \%$ for the fourth project.

Table 7 Capacity Credit of Different Solar IPP for Different Years.

\begin{tabular}{|l|c|l|l|c|}
\hline $\begin{array}{l}\text { Solar IPP } \\
\text { Projects }\end{array}$ & $\begin{array}{l}\text { Cumulative } \\
\text { Capacity } \\
(M W)\end{array}$ & $\begin{array}{l}\text { Total } \\
\text { CC } \\
(M W)\end{array}$ & $\begin{array}{l}\text { Plant } \\
C C \\
(M W)\end{array}$ & $\begin{array}{l}\text { Plant } \\
C C \\
(\%)\end{array}$ \\
\hline Ibri II (2021) & 500 & 119.36 & 119.36 & 24 \\
\hline $\begin{array}{l}500 M W \\
(2022)\end{array}$ & 1000 & 221.40 & 102.03 & 20 \\
\hline $\begin{array}{l}500 M W \\
(2023)\end{array}$ & 1500 & 295.33 & 73.92 & 15 \\
\hline $\begin{array}{l}500 M W \\
(2024)\end{array}$ & 2000 & 343.71 & 48.38 & 10 \\
\hline $\begin{array}{l}500 M W \\
(2025)\end{array}$ & 2500 & 369.36 & 25.65 & 5 \\
\hline $\begin{array}{l}500 M W \\
(2026)\end{array}$ & 3000 & 370.35 & 1.00 & 0 \\
\hline
\end{tabular}

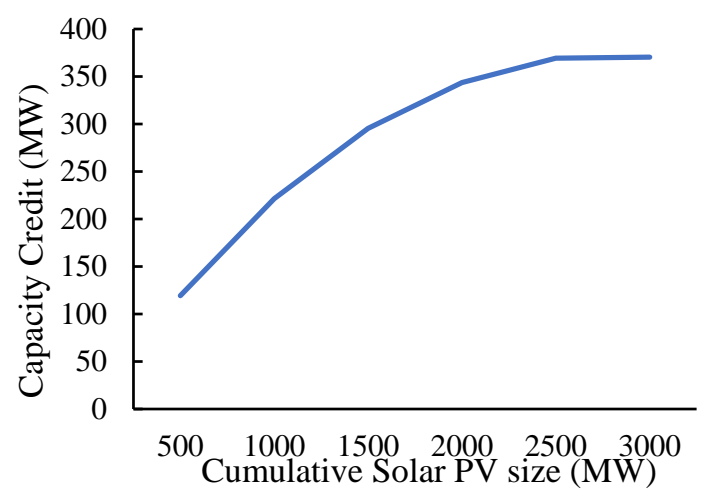

Fig. 5. Capacity Credit of Different PV Sizes

\section{Conclusions}

Capacity credit is defined as amount of additional load that can be served due to the addition of the generating unit, while maintaining the existing levels of reliability. Capacity credit calculations help policy makers in planning renewable energy capacity as well as fossil fuel-based generation capacity. There exist several methods for capacity credit calculation. These methods are classified into reliability and approximation methods. In this research, capacity factor approximation method is used for solar PV system. The study considered 21 generation units representing Oman's main interconnected system generation capacity. One-year hourly load and PV data are used. The calculation was based on comparing the loss of load probability with and without the solar PV system using MATLAB. Simulation results show that the first 500MW Solar IPP in Ibri has a capacity credit of 119.3MW. The second 500MW IPP project, which expected to be commissioned in 2022 , has a capacity credit of 102.1MW. The third 500MW IPP project, 
expected to be commissioned in 2023, has a capacity credit of $73.9 \mathrm{MW}$. The fourth 500MW IPP project, expected to be commissioned in 2024, has a capacity credit of $48.4 \mathrm{MW}$ only. It is worth noting that as cumulative solar PV capacity increases, the capacity credit of new projects diminishes.

\section{Acknowledgement}

The authors would like to acknowledge the support received from The Research Council (TRC) through Faculty Mentored Undergraduate Research Award Program (FURAP).

\section{References}

[1] International Energy Agency, Modelling the capacity credit of renewable energy sources, 2011.

[2] C. K. Simoglou, P. N. Biskas, E. A. Bakirtzis, A. N. Matenli, A. I. Petridis, and A. G. Bakirtzis, "Evaluation of the capacity credit of RES: The Greek case," in PowerTech (POWERTECH), 2013 IEEE Grenoble, 2013, pp. 1-6: IEEE.

[3] M. Khallat and S. Rahman, "A model for capacity credit evaluation of grid-connected photovoltaic systems with fuel cell support," IEEE Transactions on Power Systems, vol. 3, no. 3, pp. 1270-1276, 1988.

[4] X. Fang, Q. Guo, D. Zhang, and S. Liang, "Capacity credit evaluation of photovoltaic generation based on system reserve capacity," in Power and Energy Engineering Conference (APPEEC), 2012 AsiaPacific, 2012, pp. 1-4: IEEE.

[5] A. Keane et al., "Capacity value of wind power," IEEE Transactions on Power Systems, vol. 26, no. 2, pp. 564-572, 2011.
[6] S. Awara, H. Zareipour, and A. Knight, "Solar Power Capacity Value Evaluation-A Review," in 2018 IEEE Canadian Conference on Electrical \& Computer Engineering (CCECE), 2018, pp. 1-5.

[7] M. Milligan and K. Porter, "Determining the capacity value of wind: An updated survey of methods and implementation," National Renewable Energy Lab.(NREL), Golden, CO (United States) 2008.

[8] M. Papic, G. Preston, R. Diffely, N. Dai, M. Elkins, M. Peacock, and B. Heath, "Practical experience in evaluating adequacy of generating capacity in the Western interconnection," in 2015 IEEE Power \& Energy Society General Meeting, 2015, pp. 1-5.

[9] Y. Zhou, P. Mancarella, and J. Mutale, "Framework for capacity credit assessment of electrical energy storage and demand response," IET Generation, Transmission \& Distribution, vol. 10, pp. 2267-2276, 2016.

[10] S. Prajapati and E. Fernandez, "Capacity credit estimation for solar PV installations in conventional generation: impacts with and without battery storage," Energy Sources, Part A: Recovery, Utilization, and Environmental Effects, pp. 1-13, 2019.

[11] M. H. Albadi, "Electricity sector in Oman after 10 years of reform: Status, trends, and future perspectives," The Electricity Journal, vol. 30, no. 7, pp. 23-30, 2017.

[12] Oman Power \& Water Procurement Co. Solar Energy.Available from URL: http://www.omanpwp.com/PDF/Solar\%20Data\%20 Webpack\%20v8\%20clean.pdf

[13] Main Interconnected System , AER. Available from URL: oman.org/aer/MarketStructure.jsp

[14] S. H. Madaeni, R. Sioshansi, and P. Denholm, "Comparison of capacity value methods for photovoltaics in the Western United States," Contract, vol. 303, pp. 275-3000, 2012. 